Voix et Images

voixetimages

\title{
Table des matières du volume VII
}

Volume 7, numéro 3, printemps 1982

Anne Hébert

URI : https://id.erudit.org/iderudit/200360ar

DOI : https://doi.org/10.7202/200360ar

Aller au sommaire du numéro

Éditeur(s)

Les Presses de l'Université du Québec

ISSN

0318-9201 (imprimé)

1705-933X (numérique)

Découvrir la revue

Citer ce document

(1982). Table des matières du volume VII. Voix et Images, 7(3), 623-624.

https://doi.org/10.7202/200360ar

Ce document est protégé par la loi sur le droit d'auteur. L'utilisation des services d'Érudit (y compris la reproduction) est assujettie à sa politique d'utilisation que vous pouvez consulter en ligne.

https://apropos.erudit.org/fr/usagers/politique-dutilisation/
Cet article est diffusé et préservé par Érudit.

Érudit est un consortium interuniversitaire sans but lucratif composé de l’Université de Montréal, l'Université Laval et l'Université du Québec à Montréal. Il a pour mission la promotion et la valorisation de la recherche. https://www.erudit.org/fr/ 


\section{TABLE DES MATIERES DU VOLUME VII}

Andrès, Bernard: «Discours épistolaire et paroles en jeu», 1, pp. 191-193; “ Clopinclopant dans l'épopée: le Nouveau Théâtre Expérimental s, 2, pp. 397-400; Les États généraux du théâtre professionnel au Québec (n'en faisons pas un dramelø, 3, pp. 605-608.

Angenot, Marc: "Le nègre dans le roman blanc de S. Joachim», 1, pp. 183-186.

Audet, Noül: «L'Échappée des discours de l'oeil». 3. pp. 591-593.

Berger, Richard: «Le tirre du roman québécois des années 1940-1960\%, 1 , pp. 79-93.

Bourbonnais, Nicole: a La symbolique de l'espace dans les récits de Gabrielle Royn, 2, pp. 367-384.

Boynard-Frot, Janine: «Les écrivaines dans l'histoire littéraire québécoise, 1. pp. 147-167.

Brochu, André: a Rétrospectives er prospectives „. 3. pp. 583-590.

Choul, Jean-Claude: «xploitation et utilisation des paramètres: Ducharme, Thériault $x$, 3. pp. 571.579 .

Duquette, Jean-Pierre: "Le 'réveil rural'», 1, pp. 195-197; "Largillière ou l'art de rater le train en beauté», 2, pp. 401-403; "Rétrospective Françoise Sullivan», 3, pp. 600-602.

Fisette, Jean: «Les objets du trésor». 2, pp. $413-416$.

Godin, Jean-Cléo: aThe Arts in Canada, The Last Fify Years de W.-J. Keith et B.-Z. Shekx, 1, pp. 179-182.

Gouanvic, Jean-Marc: $\propto$ La science-fiction irrévérencieuse de Jean-Pierre April», 2. pp. 421-422.

Grenier-Normand, Lucie : «Discours romanesque et discours urbain», 1, pp. 97-117.

Hesbois, Laure: a Les monologues de Sol: une initiation à la langue-Moi», 1, pp. 119-129; a Monologues québécois de 1890 a 1980 de L. Mailhot et D.-M. Montpetit «, 1, pp. 189-190.

Jacques, Henri-Paul: «Un probable souvenir-écran chez Anne Hébert», 3, pp. 449-458.

Jones, Grahame C.: «Alexandre Chenever et Kamouraska: une lecture australienne», 2, pp. 329-341.

Kwaterko, Josef: a Le sarcasme dissident: une leciure politique du Libraire», 2. pp. 385-393.

Lavoie, Pierre et Camerlain, Lorraine: «Bibliographie de Michel Tremblay», 2. pp. 225-306.

Lévesque, Gaëtan: «Le Champion de cina heures moins dix de J.-M. Poupart», 1, pp. 187-188; «Agénor, Agénor, Agénor ex Agénor de François Barcelo», 2. pp. 423-424; a Les revues», 2. pp. 427-431; ; La revue des revues», 3, pp. $611-616$.

Major, Ruth: aKamouraska et les Enfanis du sabbat: faire jouer la transparencew, 3. pp. 459-470.

Marchand, Alain-Bernard: aLes Manuscrits de Pauline Archange: Eros et Thanatos $\$, 2$, pp. 343-349.

Michon, Jacques: « Huber Aquin et Le Théâtre au XIXen, 2. pp. 405-407. 
Novella, Novelli: «Concomitances et coïncidences dans Bonheur d'occasion», 1 , pp. $131-146$.

Paterson. Janet: «Bibliographie d'Anne Hébert», pp. 505-510.

Pestre de Almeida, Lilian: «Héloïse: la mort dans cette chambre», 3, pp. 471-482.

Poteet, Maurice: "L'Image des États-Unis dans la littérature québécoise 11755 1930/\%, 3. pp. 594-596.

Provencher, Louise: «Bibliographie d'Adrien Thério», 1, pp. 57-76. .

Robidoux, Réjean: «D'un animateur littéraire (esquisse historique)», 1, pp. 27-34.

Rousseau, Guildo: «Discours romanesque et discours urbain», 1, pp. 97-117.

Roy Lucille: «Anne Hébert ou le désert du monde». 3. pp. 483-504.

Roy-Gans, Monique: “'Le Québec est en creux' Neige noire de Hubert Aquin». 3, pp. 553-570.

Sénécal, André: : L'autorité du sentiment dans les Fiancés de 1812 2, 1, pp. 169-175.

Sirois, Antoine: «Délégués du Panthéon au Plateau Mont-Royal », 2, pp. 319-326.

Smith, André: «Théâtre au féminin: Encore 5 minutes et les Fées ont soif $\%, 2$. pp. 351-365.

Smith, Donald: “Adrien Thério: critique littéraire, animateur polémiste et romancier $x, 1$, pp. 7-26.

Thérien, Gilles: “La réussite et l'échec: Lemelin, Aquin», 2, pp. 409-411; u\$ \$ \$ et récit ». 3, pp. 603-604.

Thério. Adrien: «En marge de la vie ou le roman québécois (1900-1933)», 1 , pp. 45-55.

TURBIDE, Roch: "Michel Tremblay: du texte à la représentation», 2, pp. 213-224; “Hosanna ou la quête d'une territorialité», 2, pp. 307-318.

Vaillancourt, Pierre-Louis: “Sémiologie de l'ironie: l'exemple Ducharme», 3. pp. 513-522.

Vanasse, André: “Hommage a Jacques Allard» 1, pp. 3-4: «Du chemin Taché à la Vallée de Jonathan». 1, pp. 35-43; « Turgeon. Beauchemin, Tremblay et les autres», 2. pp. 417-419; a L'écriture et l'ambivalence, une entrevue avec Anne Hébert», 3, pp. 441-448; “De la marginalité». 3, pp. 597-599.

Vigneault, Robert: « Pierre Vadeboncoeur: l'énonciation dans l'écriture de l'essai», 3. pp. 531-552.

Voldeng, Evelyn : “ $L$ 'intertextualité dans les écrits féminins d'inspiration féministe», 3. pp. 523-530.

\section{ERRATUM}

Dans le Volume VII, numéro 2, se sont malheureusement glissées quelques erreurs que nous tenons à corriger:

- Dans le Sommaire, il fallait lire:

- BIBLJOGRAPHIE/Pierre Lavoie et Lorraine Camerlain.

- Les Manuscrits de Pauline Archange: Eros et Thanatos.

- Largilliere ou l'art de rater le train en beauté/Jean-Pierre Duquette.

- Dans la chronique de Jean-Pierre Duquette, pp. 401-403, il fallait lire Largillière et non Largillierre. 